\title{
Clinical-statistical Study on the Biomimetic Adhesion of Whole Ceramic Inlays
}

\author{
ANA MARIA BURUIANA ${ }^{1}$, FLORENTINA CORNELIA BICLESANU1*, IULIAN VASILE ANTONIAC², MARIAN MICULESCU², \\ ANCA MIHAELA PREDESCU ${ }^{3}$, VIOLETA HANCU ${ }^{1}$ \\ ${ }^{1}$ Titu Maiorescu University of Bucharest, Faculty of Dentistry, Department of Dental Specialities, 67A Gheorghe Petrascu Str, \\ 031593, Bucharest, Romania \\ ${ }^{2}$ University Politehnica of Bucharest, Faculty of Material Science and Engineering, Department of Materials Science and Physical \\ Metallurgy, 313 Splaiul Independentei Str., 060042, Bucharest, Romania \\ 3University of Medicine and Pharmacy of Craiova, Faculty of Dental Medicine, Histology department, 2 Petru Rares Str, 200349, \\ Craiova, Romania
}

Currently, a new approach to restorative dentistry is possible, from biomimetic point of view, by using restorative materials with a natural tooth-like structure and very strong adhesion to the hard remaining tissues. The objective of the study was to compare in vitro the marginal adaptation of restorations with whole ceramic inlays, using the biomimetic method compared to the classical method. A batch of 60 extracted impacted molars was used for the study. Large cavities were prepared at occlusal proximal surfaces according to minimally invasive therapy principles. The teeth were divided into 4 study groups ( $A$, $B, C, D)$. Batches $A$ and $C$ contain teeth prepared and restored through classical method, with entirely ceramic inlays. Batches $B$ and $D$ contain teeth restored through biomimetic adhesive method. After preparation, fluid composite (Gradia Direct Flo - GC) was used as a basic filling material to seal dentine wounds and dental canaliculi according to biomimetic principles. Cementing was done with Variolink Esthetic DC-Ivoclar (lot $A$ and B) and with Maxcem Elite - Kerr (lot C and D). Samples were cut and prepared for microscopic analysis. The analysis of the four batches revealed the existence of the microfissure in the dentine wounds and the presence of fragments detached from the cementing material layer. The hybrid layer is homogeneous with qualitative dental canaliculi sealing. The difference between the two methods is the size of these defects, in the case of the classical method being approximately 2 times larger. The difference between the two types of cementing material used is due to the fact that in case of Maxcem Elite - Kerrcement, discontinuities have been observed at the level of cementing material - inlay material interface. The biomimetic method is superior to the classical one, the integrity of the layers of materials used in the biomimetic treatment is clearly superior to the integrity of the layers of material used in the classical treatment.

Keywords: biomimetic method, whole ceramic inlays, cementation

Patients' demand for aesthetic restorations is on the rise, along with the interest of dentists for materials and techniques to preserve dental hard tissue, has led to the development of adhesive restorations in the posterior area.

At present, a new approach to restorative dentistry is possible, namely biomimetic approach, using restorative materials similar to the natural tooth (composite resins and ceramics) by generating a very strong adhesion to hard tissues (enamel and dentine) and reduction of polymerization shrinkage [1].

In the conventional approach, by preparing a cavity, a larger amount of dental tissue is eliminated. The decayed dental structures are replaced with rigid materials. These techniques and materials reduce the life of restorations and weaken dental rigid structures [2].

Biomimetics studies the shape, structure and function of biologically produced substances and materials, as well as biological mechanisms and processes, especially for the purpose of obtaining similar products through artificial mechanisms that imitate natural ones [3].

The primary principle of biomimetics is to restore complete dental tissue functionality by creating a strong link to the remaining tissues. This bond must support the masticatory stress, thus allowing the dental crown to regain its biological functionality and physiognomy altogether [4,
5]. Also, biomimetics allows the preservation of a larger amount of dental hard tissue, relying on the benefits of modern adhesive materials. This greatly reduces the risk of re-treatments, remaking of restoration or replacement of fillings [6].

To obtain maximum adhesive strength, the biomimetic concept involves the application of three protocols. They consist of immediate dental sealing (application of dentinal adhesives after cavity preparation, i.e. before impression) followed by applying a layer of fluid resin and raising the edges of supragingival preparation to obtain a biomimetic traction adhesive force greater than $30 \mathrm{MPa}$. These workings make the bio-base, a name used by the Academy of Biomimetic Dentistry, for the increased adhesion and reduced stressing structure of the inlay [7].

The first ceramic materials used in dentistry had limited indications for their use in the posterior areas due to the low resistance of feldspar ceramics, the occurrence of fractures representing the main reason for failure. Today, ceramic inlays can be made of high strength materials, which also offer a very close aesthetics to dental enamel [8].

The success of ceramic restorations depends on several factors: a correctly prepared cavity, a precise impression, a thorough laboratory technique, and an impeccable cementing technique [9-11]. 
Although adhesive bonding involves a complex mechanism and a longer working time, itis recommended to use it to obtain the best possible connections between inlays and dental tissues [12].

The purpose of this in vitro study is to compare the results obtained after the restoration of crown lesions stretched entirely with ceramic inlays by the biomimetic method compared to the classical method, pursuing at the microscopic level:

1. Integrity and quality of cementing material.

2. Sealing dental canaliculi.

3. Marginal Adaptation.

\section{Experimental part}

For the study a batch of 60 extracted, wisdom teeth was used. After extraction, they were cleaned by debris, brushed with prophylactic paste (Clean Polish, Kerr) and kept in physiological serum until they were prepared (fig.1).

At the level of the occlusal proximal surfaces, large cavities were prepared, both surface and in-depth, using turbine diamond-shaped spherical and cylindrical mills of various sizes, under continuous cooling with water. For finishing, fine-grained diamond drills have been used.

Teeth were divided into 4 study groups $(A, B, C, D)$.

Batches $A$ and $C$ include teeth prepared and restored by the classical method, with full ceramic inlays. The inlays of batch A were cemented with Variolink Esthetic DCIvoclar, and for batch C, Maxcem Elite-Kerr was used. After the cavity preparation (is was aimed to obtain non-retentive cavities so that insertion and disassembly of the prosthetic parts could be achieved), the teeth were taken impressions (using the method 2 phases using the Elite HD-Zhermack addition silicone as material) in order to make the prosthetic parts, which are subseguently cemented into the cavities.

Batches $B$ and $D$ are for teeth that have been restored by the biomimetic method. After preparation, the bio-base was applied by immediate dental sealing, followed by the application of a fluid composite (Gradia Direct Flo-GC). Then the teeth were taken impression for the inlays, which were then cemented into the prepared cavities. Inlays in batch B were cemented with Variolink Esthetic DC-Ivoclar, and those in batch D with Maxcem Elite - Kerr.

Protocol of applying bio-base, in study batches $B$ and $D$, is the following:

-Cleaning the cavity is achieved and it is dried with air spray.

-Acid is etched on the dental surface. Dentine lesion is etched using a 35\% phosphoric acid gel. Acid is applied to the dentine surface for 15 seconds, not more in order not to excessively etch the dentine. Excessive dentine etching is minimized using a dentinal desensitizer (Gluma Desensitizer-Heraeus Kulzer) immediately after cavity preparation. It is imperative that all steps be correctly performed and timed, rather than estimated. The acid is then removed by the spray of water and carefully dried using the air spray to prevent dehydration of the dentin, but so that no dampness remains in the cavity.

-Sterile cotton buds, saturated in $2 \%$ chlorhexidine solution, are applied in the cavity for $30 \mathrm{~s}$ to deactivate the cellular matrix metalloproteases. Then the preparation is carefully dried with sterile, dry cotton buds.

-Apply adhesive (Gluma 2Bond - Heraeus). It is then lightly dried with air spray to ensure that all surfaces are properly coated.

-Composite material is applied in a thin layer in such a way that it seals dentine surface entirely.

-It is photopolymerized for $20 \mathrm{~s}$.

Cementing protocol

- Cleaning the cavity by using sterile buds and hydrogen peroxide and dry with air spray.

-Inlay are checked. Check marginal closing.

\section{Protocol of inlays preparing}

-Etching the inlay with hydrofluoric acid should be done in the dental office before being sent to the dental technique office. The surface of the etched porcelain resembles that of engraved enamel. If it has a creamy white appearance

\begin{tabular}{|c|c|}
\hline Material & Chemical composition \\
\hline $\begin{array}{l}\text { Gradia } \\
\text { Direct Flo GC }\end{array}$ & $\begin{array}{l}\text { Aluminum silicate glass of } \mathrm{F} \\
\text { Dimetacriloiloxietil } \\
\text { Trimethylhexamethylene dicarbamate } \\
\text { Silica } \\
\text { Triethylene glycol dimethacrylate }\end{array}$ \\
\hline $\begin{array}{l}\text { Variolink } \\
\text { Esthetic } \\
\text { DC- Ivoclar }\end{array}$ & $\begin{array}{l}\text { Bis-GMA } \\
\text { UDMA- urethane dimethacrylate } \\
\text { TGDMA } \\
\text { Benzoyl peroxide }\end{array}$ \\
\hline $\begin{array}{l}\text { Maxcem Elite - } \\
\text { Kerr }\end{array}$ & $\begin{array}{l}\text { Mono, di, multimethacrylate } \\
\text { GPDM-glycerol dimethacrylate dihydrogen phosphate } \\
\text { Aluminosilicate glass of } \mathrm{Ba}, \mathrm{F} \\
\text { Nanorobium fluoride } \\
\text { Nanosilica } \\
\text { Redox system } \\
\text { Camphorquinone }\end{array}$ \\
\hline Pressed E-max & $\begin{array}{l}\mathrm{SiO}_{2} \\
\mathrm{LiO}_{2} \\
\mathrm{~K}_{2} \mathrm{O} \\
\mathrm{P}_{2} \mathrm{O}_{5} \\
\mathrm{ZrO}_{2} \\
\mathrm{ZnO}_{2} \\
\mathrm{ZnO} \\
\text { coloring oxides } \\
\end{array}$ \\
\hline $\begin{array}{l}\text { Gluma 2Bond - } \\
\text { Heraeus }\end{array}$ & $\begin{array}{l}\text { Ethanol } \\
\text { HEMA (2 hydroxyethyl methacrylate) } \\
\text { Poly (methacrylate-oleo-acrylic acid) } \\
\text { 4-methacryloxyethyltrimelitic anhydride } \\
\text { Glutaral } \\
\text { Diurethane dimethacrylate }\end{array}$ \\
\hline
\end{tabular}

Table 1

CHEMICAL COMPOSITION OF MATERIALS USED [13-15] 
close to the snow appearance, itmeans that the restoration has been etched in excess. The situation can be remedied using ethanol and ultrasound. A 35\% phosphoric acid gel application for 15 seconds will clean the surface of the coat.

-Silane is applied on the inlay. Using a bicomponentsilane (Bis-Silane - BISCO) allows the creation of a very active ceramic surface. The two parts of the silane are mixed before application for a fresh chemical bond. Then apply two layers of silane on the dry restoration surface. After 30 $s$, the residual solvent is evaporated with dry air and without oil. A properly etched and treated with silane surface will have a satin finish.

- The cavity is again cleaned and it is dried with air spray from the dental chair unit.

\section{Protocol of cavity preparing}

- Dental surface is etched. For batch $A$, the tooth is etched differentially using $35 \%$ phosphoric acid gel. The acid is initially applied to the surface of the enamel for $15 \mathrm{~s}$, then applied to the dentine surface for another 15s. Thus, enamel etching is obtained without the risk of excessively injurying the dentine. The acid is then removed with a spray of water and carefully dried, using the air spray, to prevent dehydration of the dentine, but so that no moisture remains in the cavity. In the case of betch B teeth, only the acidic etching of the enamel surface is performed, as the dentine lesion is protected by the previously made bio base.

-Apply $2 \%$ chlorhexidine in the cavity. It rehydrates the dentine (in the case of the batch $A$ teeth), if it has been dehydrated by excessive drying in the previous step. Apply sterile cotton buds into the cavity, saturated in $2 \%$ chlorhexidine solution for $30 \mathrm{~s}$. Then the preparation is dried carefully with sterile dried cotton buds.

-Apply the adhesive. The adhesive is applied both to the surface of the inlay and to the surfaces of the dental cavity. This layer acts as a wetting agent for resin cement. It is recommended to photopolymerize the adhesive after correctly placing the prosthesis in the cavity. This reduces the appearance of inadequate coat locations due to an inadequate thickness of the adhesive layer.

-Apply cement resin. Resin cement is applied to both the inaly and into the cavity.

-Insert the inlay into the cavity. The inlay mustbe oriented so that it is easily inserted into the cavity.

-Photopolymerize the resin cement for about 2 sto obtain a gel consistency.

-Restoration margins are covered with a glycerin layer while polymerization is completed. This prevents the inhibition cement with oxygen.

Check and finish the marginal shutdown. Finishing is done with the fine diamond drill.

As a result of restoration, vertical sections were made at the teeth level in order to study the proposed objectives under a microscope.

\section{SEM protocol}

The teeth were prepared for microscopic analysis using a materialographic preparation line (manufacturer Buehler $\mathrm{GmbH}$ ) consisting of IsoMet 4000 precision cutting machine, vacuum embedded samples machine and Vector polishing machine. Samples were longitudinally sectioned by diamond disk cutting under continuous cooling with inert liquid and subsequently vacuum-embedded in selfcuring resin Buehler Epo-Kwik (FastCure Epoxyresin) using special molds. Polishing and glazing were done with the automatic machine (it contains a rotating base disk on which abrasive papers and magnetic contact lenses are placed and a programmable vector head on which four samples are simultaneously pressed on an individual basis by means of pistons) according to own protocol, carried out step by step, using abrasive paper containing SiC particles successively starting from P320 and reaching up to P2000. After each step the samples were washed and dried. For polishing, a five-step method was also used. Special cloths that were impregnated with Polycristalline diamond water based suspension with particles from 15 microns to 1 microns (steps were 15, 9, 6, 3, 1 microns) were used. Final polishing was performed using a 0.05 micron particle based colloidal silica suspension. The samples thus prepared were then analyzed on the electronic scanning microscope (ESEM Philips XL30).

\section{Results and discussions}

SEM analysis of A batch (the classical method, Variolink Esthetic DC-Ivoclar cementation) revealed the presence of dentine microfissures with lengths between 10-40 $\mu \mathrm{m}$. It was also possible to see some dislodged fragments of the cementing material between 30-100 $\mu \mathrm{m}$, which generated cracks propagating in the dentine substrate of approximately the same length. The hybrid layer is largely homogeneous, showing little fracture traces in its thickness. Sealing of dentinal canaliculi is superior, the thickness of the hybrid layer varying between 5 and 20 $\mu \mathrm{m}$. However, in the thickness of the cementing material there were observed areas of non-homogenized particles (fig.1-5).

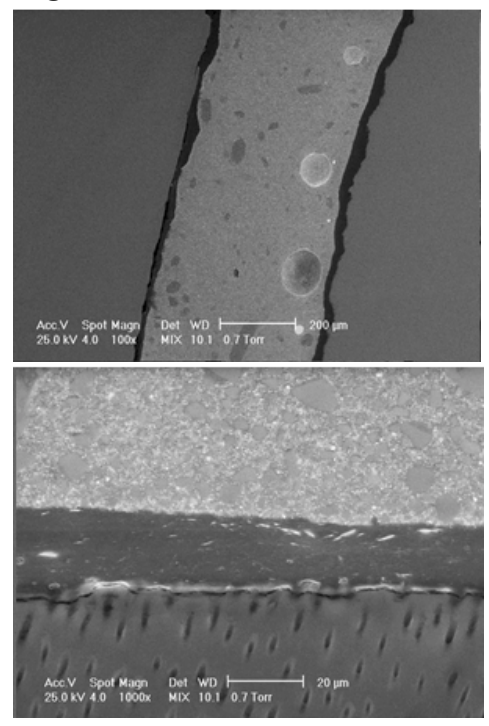

Fig.1. Cementinlay interface

Fig.2. Cement-dentine interface. In cross section dental tubes can be noticed. Between dentine and the meterial there are gaps.

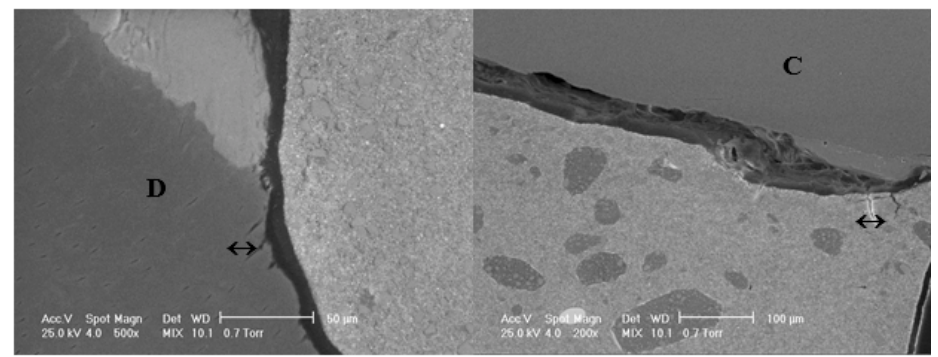

http://www.revistadechimie.ro
Fig.3. Microfissures occurrence 

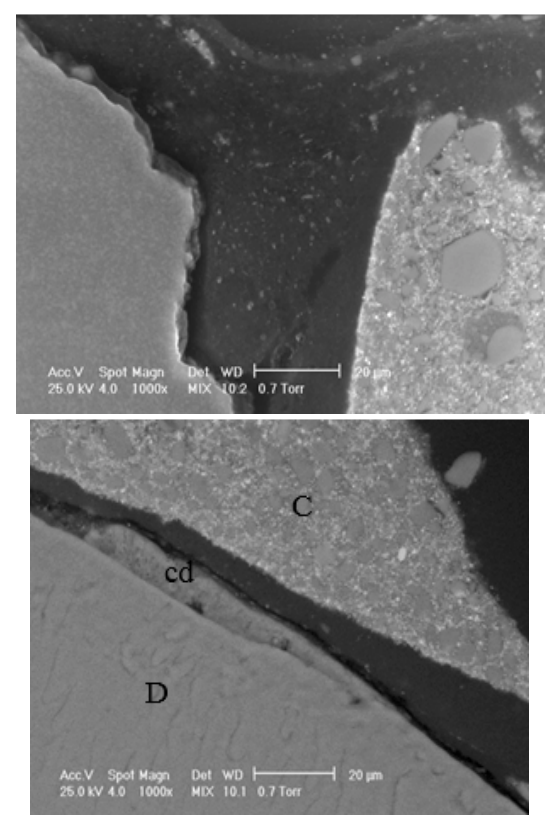

Fig.4. The

appearance of the hybrid layer and the sealing of dentine canaliculi. (cd - dentine canaliculi)

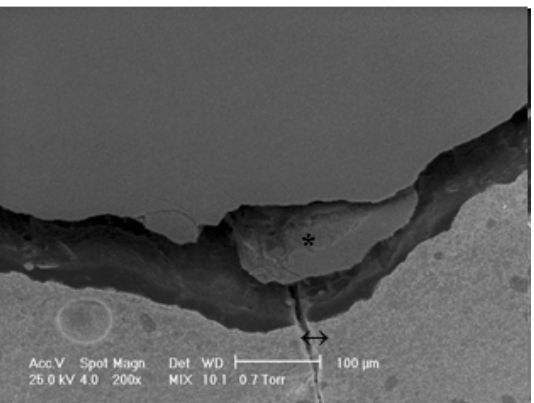

Fig.5. Fractured fragment $(*)$ in the thickness of the cementing material layer layer and microfissure $(\leftrightarrow)$ generated by it

The SEM analysis of the $C$ batch (classical method, cementation with Maxcem Elite - Kerr) revealed, as in case of batch $A$, the presence of the microfissures $(\leftrightarrow)$ from the dentine lesion of 2-3 $\mu \mathrm{m}$ but in a lower proportion. Fragments of cement fractured on lenghts between 10-20 $\mu \mathrm{m}$ were also observed, but in this case they no longer generated crack lines in the dentine. The hybrid layer is integral with a good closure of the dental canaliculi, of thickness between 5 and $25 \mu \mathrm{m}$. Within this batch of teeth, however, discontinuous surfaces at the inlay-cement interface are present, with lengths between 10-20 $\mu \mathrm{m}$ and a width of about $1 \mu \mathrm{m}$. Non-homogenized particles can also be observed in this cement (fig. 6-13).

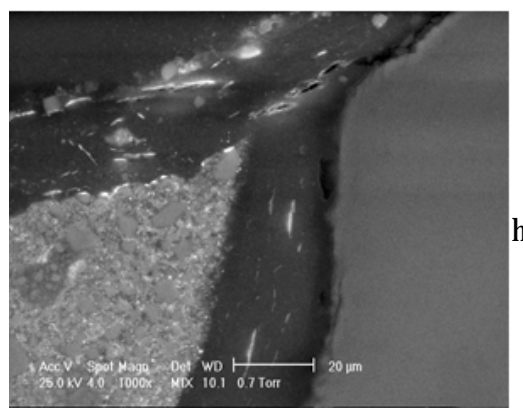

Fig.6. Aspect of nonhomogenized particles in the thickness of the cementing material

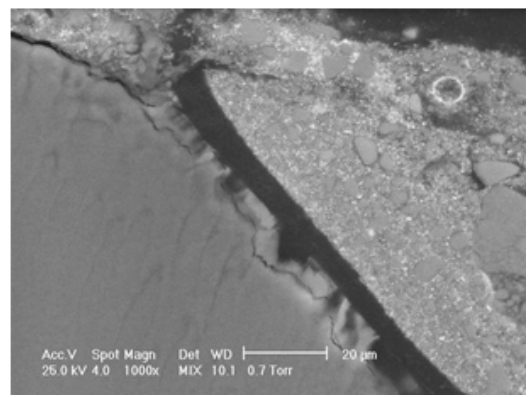

Fig.7. Presence of discontinuous areas at inlay-cement interface level and gap areas. Dentine canaliculi can be observed on crosssection.

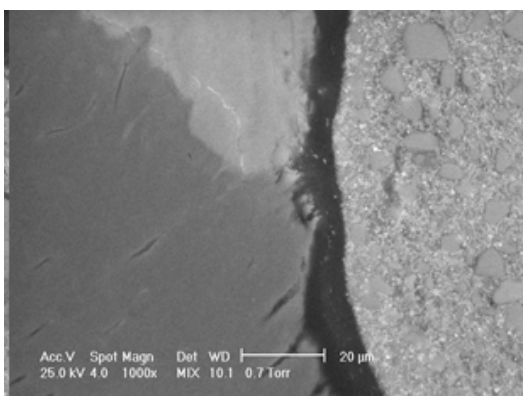

8. Hybrid layer aspect

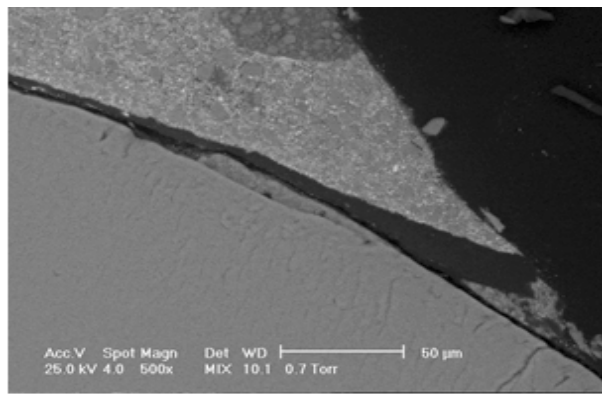

Fig.9. The appearance of the fissures at dentine lesions level.

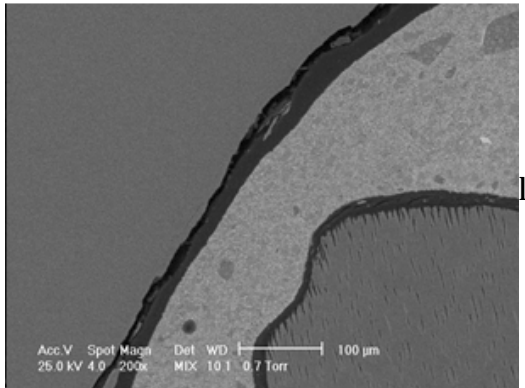

Fig.10. The presence of air bubbles in the thickness of the cement layer, the sealing material penetrates into dentine canaliculi (cd) on distances of 10-20 $\mu \mathrm{m}$
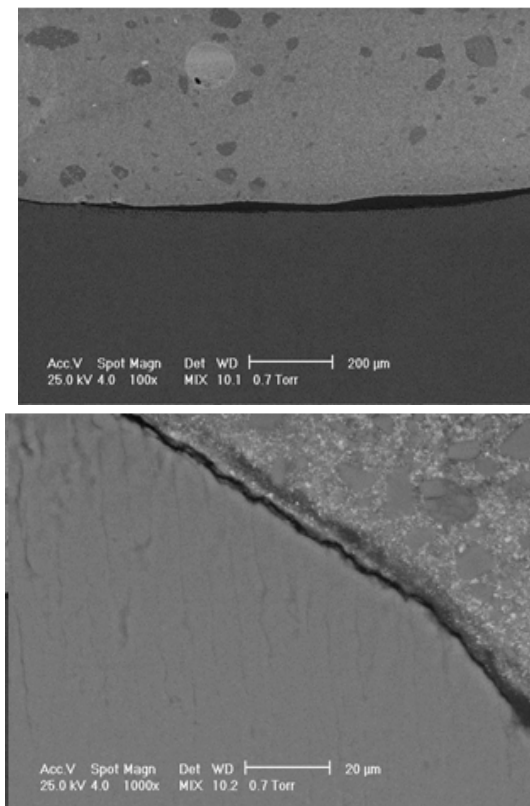

Fig.11. Appearance of the hybrid layer, which has a clear contour

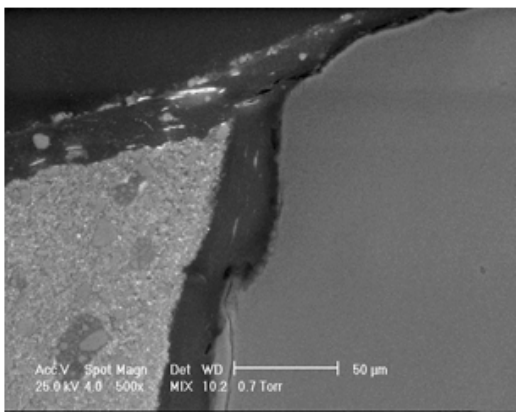

Fig. 12.

Non-homogenized particles. 


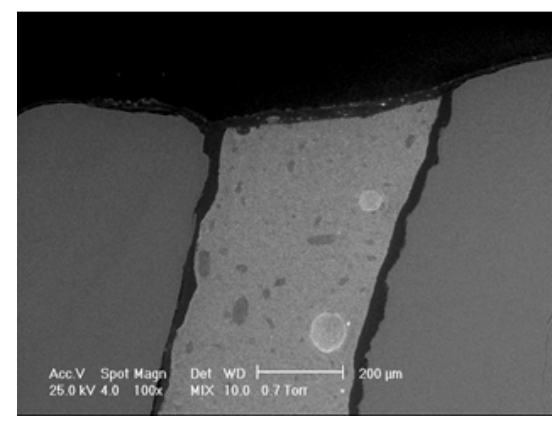

Fig.13. Tooth-materialinlay interface

SEM analysis of $B$ batch (biomimetic method, Variolink Esthetic DC-Ivoclar cementation) revealed a homogeneous hybrid layer, with a thickness of 5 to $25 \mu \mathrm{m}$, with good sealing of the dentine canaliculi. The presence of fissures at dentine lesions level with lengths betw een 2-15 $\mu \mathrm{m}$ was observed. However, it is rare to see the fractured fragments in the cementing material layer, which has maximum lengths of $5 \mu \mathrm{m}$, but does not generate microcracks. The inlay-cementing material interface is homogeneous. It is also observed in this case the presence of non-homogenized particles zones in the thickness of the cement layer (fig. 14-18).

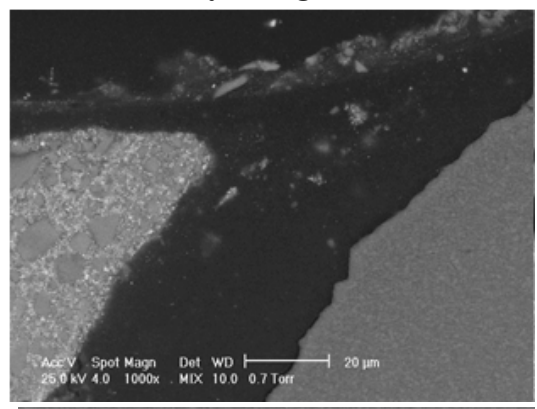

Fig.14. Inlay-cementing material interface
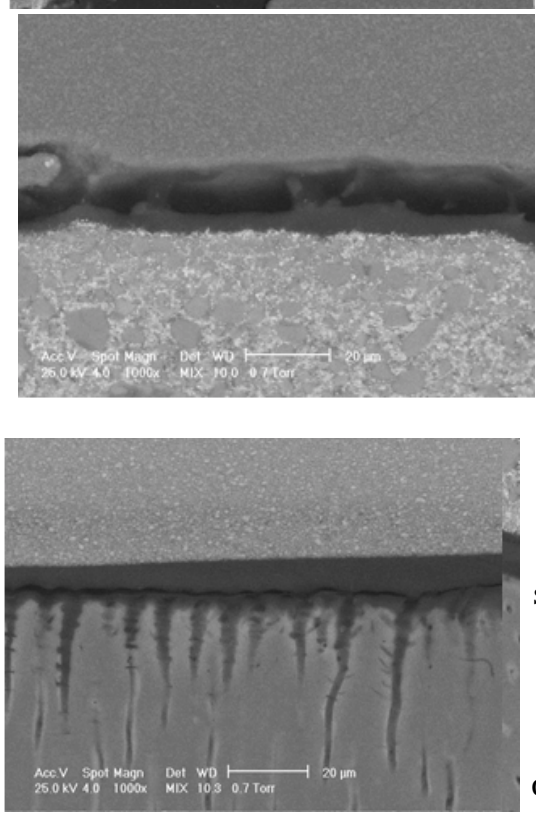

Fig.15. Appearance of dentine canaliculi on longitudinal section. Dentinal tubules and sealing material parcicles can be seen which entered on variable distances the depth of canaliculi. Peritubular dentine is more intensily mineralized.

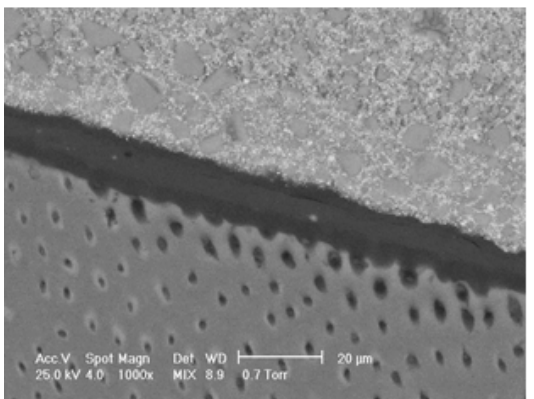

Fig.16. Appaerance of dentine canaliculi on cross section, uniformly distributed within the dentine, clear halo, which can be determined by dehydration of odontoblastic process

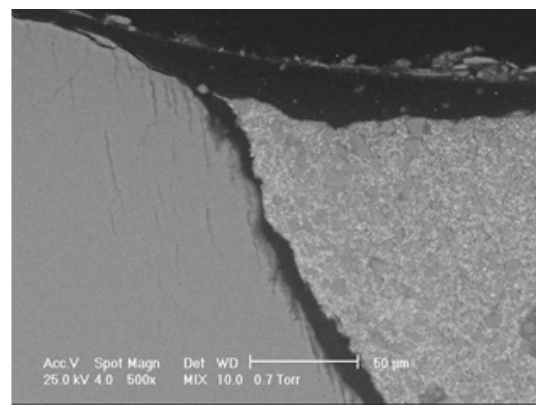

Fig.17. Appearance of

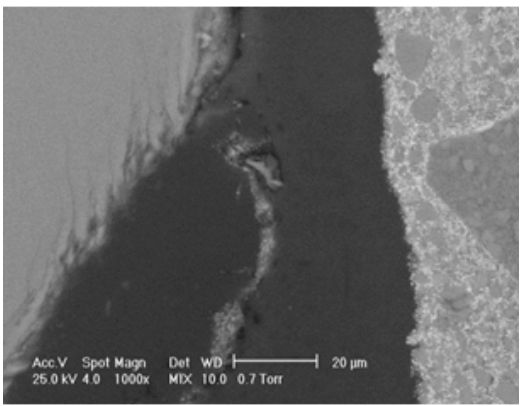

microfissures at

dentine lesions level.

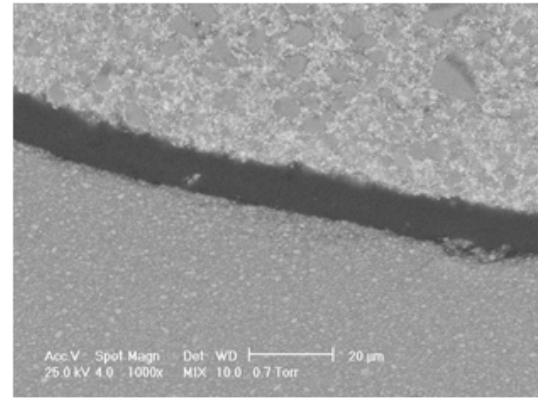

Fig.18. Appearance of cementing material-

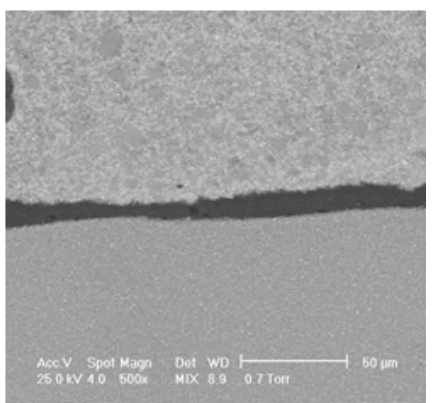

inlay interface.

SEM analysis of $D$ batch (biomimetic method, cementation with Maxcem Elite - Kerr) also highlighted a homogeneous hybrid layer of 5-20 $\mu \mathrm{m}$ thickness. Sealing dentine canaliculi is also qualitative. There are fractured fragments of the cement layer with a length of $20 \mu \mathrm{m}$, but they do not generate cracks. However, the existence of microfissures in dentine lesions with lengths up to $20 \mu \mathrm{m}$ is observed. At the inlay-cementing material interface, discontinuities up to $10 \mu \mathrm{m}$ wide are present. Also in this case, as in the other batches of teeth analyzed, non homogenized particles occur in the cement layer (fig.1924).

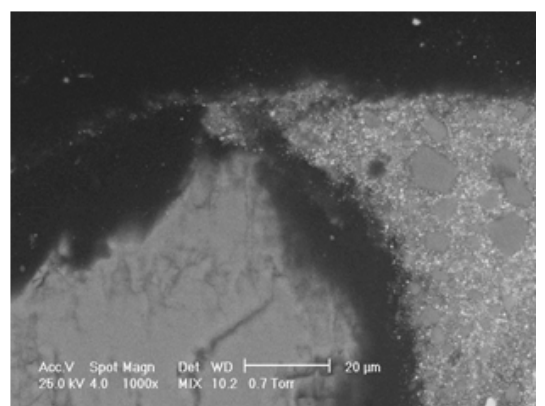

Fig.19. Appearance of fissures in dentine. 


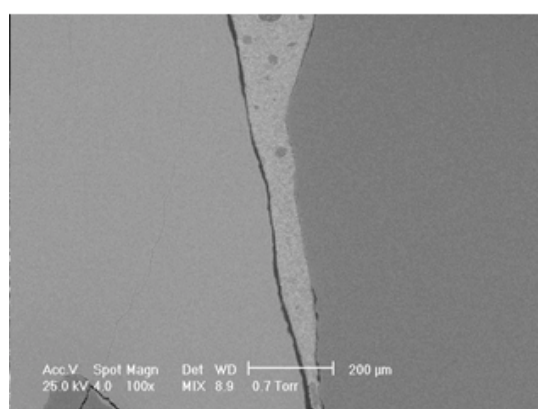

Fig.20. Appearance of dentine-materialinlay interface

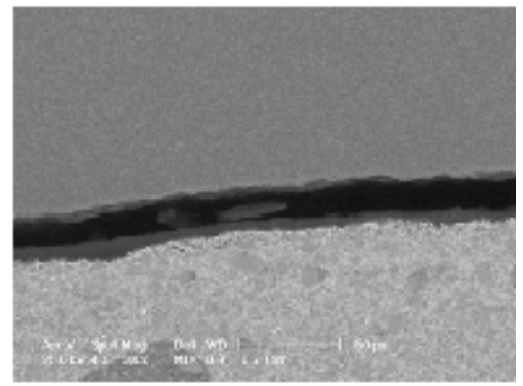

Fig.22. Fractured fragment

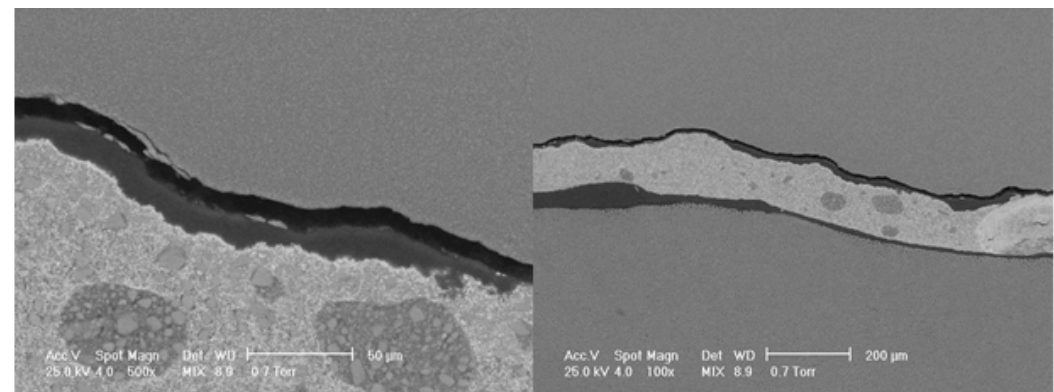

Table 2

RESULTS OF THE STUDY

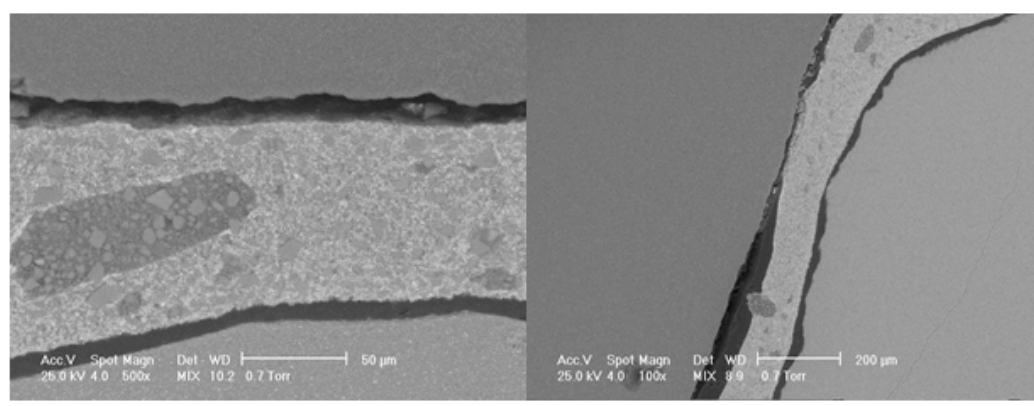

Fig.21. The appearance of fractured fragments from the thickness of the cement layer

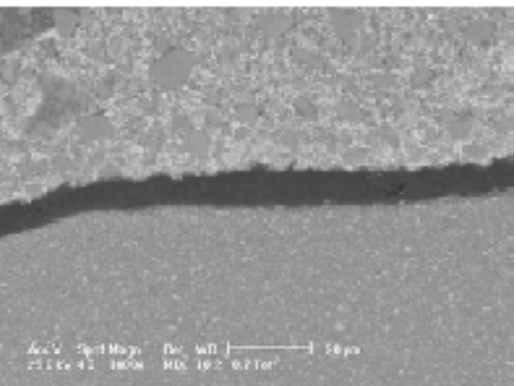

Fig.23. Appearance of the contour hybrid layer less net than the previous batch.

Fig.24. Aspect of discontinuity at the inlaycementing material interface.

\begin{tabular}{|c|c|c|c|}
\hline \multicolumn{2}{|c|}{ Classical method } & \multicolumn{2}{|c|}{ Biomimetic method } \\
\hline Maxcem & Variolink & Maxcem & Variolink \\
\hline $\begin{array}{l}\text {-the hybrid layer ( } 5 \text { and } 25 \\
\mu \mathrm{m}) \text {; } \\
\text { - microfissures at dentine } \\
\text { lesions level }(2-3 \mu \mathrm{m}) \text {; } \\
\text {-fragments of fractured } \\
\text { cement }(10-20 \mu \mathrm{m}) \text {, but in } \\
\text { this case they have not } \\
\text { generated any crack lines; } \\
\text { - discontinuous surfaces at } \\
\text { the inlay-cement interface } \\
\text { (with lengths between } 10 \text { - }\end{array}$ & $\begin{array}{l}\text { a mostly homogeneous } \\
\text { hybrid layer, showing small } \\
\text { fragments of fracture in its } \\
\text { thickness ( } 5-20 \mu \mathrm{m}) \text {; } \\
\text { - dentine microfissures ( } 10-40 \\
\mu \mathrm{m}) \text {; } \\
\text { - fragments detached from the } \\
\text { cementing material ( } 30-100 \\
\mu \mathrm{m}) \text {, which generated cracks } \\
\text { propagating in the dentine } \\
\text { substrate of approximately }\end{array}$ & $\begin{array}{l}\text {-homogeneous hybrid layer } \\
\text { ( } 5-20 \mu \mathrm{m} \text { ); } \\
\text { - dentine lesions } \\
\text { microfissures (up to } 20 \mu \mathrm{m} \\
\text { long); } \\
\text { - fractured fragments of the } \\
\text { cementing material layer (up } \\
\text { to } 20 \mu \mathrm{m} \text { long), but they do } \\
\text { not generate cracks; } \\
\text { - there are discontinuities (up } \\
\text { to } 10 \mu \mathrm{m} \text { wide) at the inlay- }\end{array}$ & $\begin{array}{l}\text { - homogeneous hybrid } \\
\text { layer }(5-25 \mu \mathrm{m}) \text {; } \\
\text { - dentine lesions } \\
\text { microfissures }(2-15 \mu \mathrm{m}) \text {; } \\
\text { - fractured fragments of } \\
\text { the cementing material } \\
\text { layer (up to } 5 \mu \mathrm{m}) \text {, but } \\
\text { they do not generate } \\
\text { cracks; } \\
\text { - the inlay-cementing }\end{array}$ \\
\hline
\end{tabular}

This study compares the classical method of restoration of carious and biomimetic lesions, while comparing the performance of the two cement materials used, namely Maxcem Elite - Kerr and Variolink Esthetic DC - Ivoclar.

In the case of the classical method, discontinuity zones appear at the internal contour level, which can be the source of further failures. Thus, the integrity of the material layer is affected, but also the sealing of the dentine canaliculi.

In the case of the biomimetic method, the results are superior, since no defects affecting the integrity of the cementing material or of the base filling material have been observed.

We have chosen to use as a composite fluid-based filling material as this indicates the biomimetic protocol, thus benefiting from the bond created by the adhesive layer, compared to the bond that is created betw een the dentine substrate and the glass ionomer cements.
Magne states in 2006 that glass ionomer cements are very useful in deep cavities with the indication to be used as a basic filling material [5].

Collares K et al. demonstrated in 2016 that the use of a glass ionomer cement base filling under indirectrestoration with ceramic inlay resulted in a double degradation risk compared to cases in which the glass ionomer cement was not used [16].

Ngo also argues that these cements are successfully used in deep V-class cavities, their properties such as fluoride release, bacteriostatic effect, and the ability to remineralize dentine, categorizing them as biomimetic materials [17].

Wilson R. argues that using the biomimetic method increases the chances of conserving the dental pulp. He states that in the deep cavities in which, if the exeresis of the entire caried tissue, the pulp chamber would open if a thin layer of altered dentine was left in the pulp chamber 
so that it remained closed, and then the cavity is filled according to the biomimetic principles, the pulp can be preserved. Practically this technique is similar to that of natural arranging used in pedodontics. The primary condition is that the tooth has not shown any symptoms in its medical history. Wilson states that studies have shown that as long as the deeply residual carious tissue is correctly sealed, it will not evolve, as the caries bacteria are thus deprived of oxygen and sugar, which are their source of development, and so they remain in a latent state [18].

Biomimetics emphasizes the link between restoration and residual dental tissue, which is an important parameter in the success and longevity of the treatment. In our study, in the teeth in batches $\mathrm{A}$ and $\mathrm{C}$, the dentine canaliculi sealing is reduced, due to the discontinuity zones present at the dentine lesion - cementing material interface. For teeth in batches B and D, the dentine lesions sealing is superior, the discontinuity zones being very small or nonexistent. Hence, the superior quality of the hybrid layer can be deduced in the case of restored teeth by the biomimetic method.

In the last decade, a great deal of emphasis has been placed on the importance of the integrity of the hybrid layer. Developing modern adhesive techniques has increased the longevity and sustainability of restorative treatments.

There are two fundamental processes involved in creating the bond between the adhesive and the dentine, namely: removing the mineral substrate from the dentine lesion, but without collagen matrix wound, and filling the voids left by the mineral with the adhesive resin, i.e., the formation of a resin or hybrid resin layer. In order to obtain an ideal hybrid layer, the adhesive application should result in a three-dimensional polymer-collagen network that ensures a stable and continuous bond between the adhesive and the dentin. Research shows that this ideal goal has not yet been reached [19-21].

The adhesion and realization of a hybrid layer as close as possible to the ideal is a controversial topic, which has led to numerous studies on this subject.

In vitro and in vivo studies suggest that the factors responsible for inhibiting the formation of a durable bond between the adhesive and dentine are water absorption and hydrolysis of the adhesive resin, inadequate monomer/ polymer conversion of the adhesive, incomplete resin infiltration, incomplete solvent evaporation [22 -25].

Ana Sezinando stated in 2014 that adhesive systems containing hydrophobic resin are able to better prevent water degradation compared to those that do not, irrespective of the application technique. However, the performance of adhesive systems is dependent on their chemical composition [26-29].

The present study reveals that, by using the biomimetic method, a higher quality hybrid layer is obtained compared to the classic method of restoration, but in this case no continuous and stable hybrid layer is obtained, as it is desirable to microscopically detect the small defects of it.

The adhesive used in this study is Gluma 2Bond - Heraeus Kulzer, which is an adhesive of 5 generation. The obtained hybrid layer has variable thicknesses ranging from 5 to 25 $\mu \mathrm{m}$. Its quality is satisfactory compared to other types of adhesives. In 2014, Dr. Geeta Asthana and Dr. Girish Parmar conducted a study on the hybrid layer. Their conclusion is that although they are much easier to apply, all-in-one adhesives have not produced effective linkages, with totaletch adhesives being still the reference point when itcomes to dentine adhesives, among which the adhesive which we used in our study [30].

In 2015, Adad W. et al. concluded as a result of their study that three-step total-etch adhesives create a more effective relationship with other types of dentine adhesives in spite of prolonged working time. They also demonstrated that the use of chlorhexidine after acidic etching is a viable procedure for obtaining greater longevity of the hybrid layer in dentine [31].

In 2016, Singh A. et al. concluded that the use of $2 \%$ chlorhexidine solution increases the bond strength of the hybrid layer [32].

Also, in 2010, Shafie F. et al. demonstrated, following their study, that the introduction of chlorhexidine into the therapeutic protocol reduced marginal microinfiltration in the gingival margin [33].

Although the hybrid layer created by separate acid etching systems is thicker than the self-etched systems, the comparison of the bond strength between the two generated controversial results. The thickness of the hybrid layer does not play a key role in the success and dentinal bond strength, which is likely proportional to the quality of the hybrid layer. Both self-etched and self-etched adhesive glues have been shown to form a continuous and uniform hybrid layer [34-36].

Several studies have assessed the bond strength (shear and traction) to the dentine near the enamel-dentine junction. Yaseen etal. compared the shear binding force of two self-etching systems (generations 6 and 7) and Senawongse et al. measured the adhesion resistance of separate acid etching adhesive (Single Bond) and selfetching (Clearfil SE Bond) for primary dentine. They have failed to find a significant difference between different adhesion systems. Higher shear resistance reported in their studies can be attributed to the morphological differences of the dentine in different areas of the tooth, and also to the difference in cross-sectional area dimension in which the load is applied.

Muller V. et al. conducted a comparative study in 2017 that looked at the quality of marginal sealing of three types of adhesives and cementing materials: Scotchbond Universal + Rely X Ultimate, Monobond Plus, Syntac + Variolink II, Clearfil Ceramic Primer + Panavia SA Cement. The results show that there are no significant differences [40].

In 2016, Abad-Coronel Cristian et al. conducted a study in which they investigated the performance of 4 cementing materials (RelyX, Multilink, PANAVIA 2.1, Maxcem), concluding that there are no significant differences, when considering the marginal microinfiltration, among the cements used [41].

Also in 2016 Patroi et al. performed a study on adhesive cement using 3 types of cement resin materials and 3 types of adhesives: Dualcim cement + Dentadez Photo Adhesive, Nexus NX3 + cement Optibond Solo Plus, Variolink II + cement, adhesive Syntac + Heliobond. The results showed that the adherence of Variolink cement to dentine was significantly higher than for the other two composite cements, Nexus and Dualcim, but there was no significant difference between enamel and dentine for the three types of materials [12].

In 2009, Uludag et al. conducted a comparative study using 3 types of cementing materials (RelyX ARC, Variolink II, Panavia 21) and 4 types of adhesives (Single Bond, ExciTE DSC, ED Primer, Admira Bond). Thus, each cementing material was used together with each dentine adhesive, the ceramic inlays being thus cemented with 12 types of cement-adhesive combinations. The microinfiltration observed in the dentine substrate was significantly higher than that of the enamel in all cases [42].

Interactions between oral microbes and dental resins may also occur, although today not very numerous 1940 
information are available regarding this possibility [43]. The requirements for an acceptable dental material are many, but one of the most important is the biocompatibility [44].

Biomimetic dentistry offers conservative solutions with beneficial results in extensive carious lesions. In order to be able to benefit from the maximum results of dentistry and current products, it is necessary to strictly observe all the therapeutic steps as well as the time intervals of application of the products in the cavity, and notestimated, as these details make the difference between failure and success.

\section{Conclusions}

The research suggests that the biomimetic method is superior to the classical method, since the integrity of the layers of materials used in the biomimetic treatment is superior to the integrity of the layers of material used in the classical treatment.

\section{References}

1.MAGNE P, BELSER U. Bonded Porcelain Restorations in the Anterior Dentition: A Biomimetic Approach. Chicago, IL: Quintessence Publishing; 2002.

2.GOSWAMI S. J Oral Res Rev 2018;10:28-32.

3.KOTTOOR J, Health Sciences, 2(1), 2013, JS007.

4.MCMAHON S.M, EVRON E, Biomimetic principles applied to cosmetic dentistry, 4(7), 2011.

5.MAGNE P, CDA. Journal, 34(2), 2006.

6.*** https://www.quora.com/ls-biomimetic-dentistry-different-orbetter-than-regular-dentistry-techniques

7.ALLEMAN DS et al, 2017. Inside Dentistry, 13(6)

8.CHRISTA D. HOPP, MARTIN F. LAND, Clinical, Cosmetic and Investigational Dentistry 2013:5, 21-32.

9.BACIU S, FOREA A, MANOLE M, et al., Mat. Plast., 52 , no. 2 2015, p. 214.

10.BACIU, S, FOREA, A, MANOLE, M, et al. Mat. Plast., 52, no.3, 2015, p.391.

11.MANOLE, M, BERECE, C, FLOREA ,A, et al. Rev. Chim.(Bucharest), 68, no. 8, 2017, p. 1919

12.PATROI, D.N, MOLDOVEANU, G, HANCU, V, BOTOACA, O, COMANEANU, R.M, BARBU, H.M. Rev. Mat. Plast, 53, no.1, 2016.

13.***http://ww w.scritub.com/medicina/MATERIALE-DENTARE 242414313.php

14.*** http://www.roedentallab.com/downloads/emaxpressdata.pdf 15.FERRACANE JL, STANSBURY JW, BURKE FJ, J Oral Rehabil. 2011 Apr;38(4):295-314.

16.COLLARES K, CORREA MB, LASKE M, et al, Dent Mater. 2016 May;32(5):687-94.

17.NGO H, Biological properties of glass-ionomers In: An atlas of glass-ionomer cements. A clinician's guide, Martin Dunitz, London, 2002, 43-55.

18.*** https://www.pomeradocosmeticdentistry.com/practice-news/ can-biomimetic-dentistry-prevent-root-canals-san-diego-cosmeticdentist-explains/
19.SPENCER P, WANG Y, BOHATY B.J Biomed Mater Res B. 2006;77:234240.

20.WANG Y, SPENCER P. J Dent Res. 2005;84:350-354.

21.SPENCER P,YE Q, PARK J, TOPP E.M, et al, Ann Biomed Eng. 2010 June ; 38(6): 1989-2003.

22.BRESCHI L, MAZZONI A, RUGGERI A, et al. Dent Mater. 2008;24:90101.

23.FERRACANE JL. Dent Mater. 2006;22:211-222.

24.WANG Y, SPENCER P, YAO X, BRENDA B. J Biomed Mater Res A. 2007:82:975-983.

25.YE Q, SPENCER P, WANG Y, MISRA A. J Biomed Mater Res A. 2007; $80: 342-350$.

26.VAN MEERBEEK B, YOSHIHARA K, YOSHIDA Y, MINE A, DE MUNCK J, VAN LANDUYT KL. Dent Mater. 2011;27:17-28.

27.MUNOZ MA, SEZINANDO A, LUQUE-MARTINEZI, SZESZ AL, REISA, LOGUERCIO AD, et al. J Dent. 2014;42:595-602.

28.SEZINANDO A, PERDIGÃO J, REGALHEIRO R, J Esthet Rest Dent, 24 (2012), pp. 345-356

29.SEZINANDO A, Medicina Dentária e Cirurgia Maxilofacial 2014; 55(4): 194-206.

30.ASTHANA G, PARMAR G. 2014, Vol. 01, Issue 01, p. 46-50.

31.ADAD W, TELLES PIRES C, GABRIELLI AC, MEIRELLES M, AFFONSO BARRETTO A. Rev Gauch Odontol, Porto Alegre, v.63, n.1, p. 55-62, jan./mar., 2015.

32.SINGH A, MADAN G, AGRAWAL RS, AKOLKAR A, GUPTA S, KEWALRAMANI N, International J ournal of Oral Care and Research, October-December 2016;4(4):263-266.

33.SHAFIE F, DOOZANDEH M, ALAVI A. J Dent (Tehran). 2010 Winter;7(1):31-40. Epub 2010 Mar 31.

34.ALBALADEJO A, OSORIO R, TOLEDANO M, FERRARI M. Med Oral Patol Oral Cir Bucal. 2010; 15(1): el12-8.

35.SAKAGUCHI RONALD L, POWER J OHN M. Craig's restorative dental materials. 13th ed Philadelphia: Mosby; 2012: chp 13: 329.

36.AFSHAR, H., BARADARAN NAKHJAVANI, Y., RAHRO TABAN, S., BANIAMERI, Z., \& NAHVI, A. (2015). J ournal of Dentistry (Tehran, Iran), 12(2), 90-98.

37.YASEEN SM, SUBBA REDDY VV.J Indian Soc Pedod Prev Dent. 2009. Jan-Mar 27 (1): 33 - 8.

38.SENAW ONGSE P1, HARNIRATTISAI C, SHIMADA Y, TAGAMI J. Oper Dent. 2004. Mar-Apr; 29(2): 196- 202.

39.AFSHAR, H., BARADARAN NAKHJAVANI, Y., RAHRO TABAN, S., BANIAMERI, Z., \& NAHVI, A. (2015). Journal of Dentistry (Tehran, Iran), 12(2), 90-98.

40.MULLER V, FRIEDL KH, FRIEDL K, HAHNEL S, HANDEL G, LANG R, Clin Oral Investig. 2017 Mar;21(2):607-612.

41.ABAD-CORONEL C, LI J, MARTíNEZ-RUS F, PRADÍES G. Hindawi Publishing Corporation International J ournal of Dentistry Volume 2016, Article ID 8084505, 5 pages.

42.ULUDAG B, OZTURK 0, OZTURK AN. J Prosthet Dent. 2009 Oct; 102(4):235-41.

43.BECHIR, A., PACURAR, A., BECHIR, E.S., COMANEANU, M.R., et al, Mat Plast, 51, no. 1, 2014, pp. 54-61.

44.BECHIR, A, BECHIR, ES., MANU, R., et al, Mat Plast, 53, no. 4, 2016

Manuscript received: 21.01 .2019 